\title{
A STUDY TO DETERMINE PSYCHOPATHOLOGY, PSYCHIATRIC MORBIDITY AND TEMPERAMENT IN EPILEPTIC CHILDREN
}

\author{
Nikhil P. Chougule1, Kaveri Nikhil Chougule2, Sanjiv S. Kale3, Prakash B. Behere ${ }^{4}$ \\ ${ }^{1}$ Assistant Professor, Department of Psychiatry, Dr. D. Y. Patil Medical College and Hospital, Kolhapur. \\ ${ }^{2}$ Senior Resident, Department of Psychiatry, Dr. D. Y. Patil Medical College and Hospital, Kolhapur. \\ ${ }^{3}$ Professor and HOD, Department of Psychiatry, Dr. D. Y. Patil Medical College, Nerul, Navi Mumbai, Maharashtra. \\ ${ }^{4}$ Vice Chancellor, D. Y. Patil Education Society, (Deemed University), Kolhapur.
}

\begin{abstract}
\section{BACKGROUND}

Children with epilepsy are at increased risk for behavioural problems compared to the general population or control groups. A study of psychopathology, psychiatric morbidity and temperament in children suffering from epilepsy in comparison to normal healthy children in a tertiary care teaching hospital forms the basis of this study. The aim was to study the prevalence, common psychological problems, the factors contributing to these problems and the effect of the illness on the outcome of the biological, psychological and social growth of the children.
\end{abstract}

\section{MATERIALS AND METHODS}

A proforma along with standardised scales were used. Fifty children in the age range of 4-14 years attending the Paediatric Epilepsy Clinic, along with 50 normal children from the General Paediatric OPD constituted the study and the control group respectively. After obtaining the informed consent from the parents, the children and their parents were interviewed on the basis of the proforma. The data thus collected was tabulated and statistically analysed.

\section{RESULTS}

Nearly half of the children from the study group had at least some psychiatric disturbance. In comparison only one fourth of the children from the control group displayed any psychiatric disturbance. The most common psychiatric problem in the epileptic child was conduct disorder followed by a lowered intelligence, whereas in the non-epileptic child anxiety and conduct disorder was common. Various factors were found to be significantly associated with psychopathology, these were either contributory to the epilepsy or were consequent to the epileptic state along with its biological, psychological and social ramifications.

\section{CONCLUSION}

Psychiatric morbidity is a common problem in children suffering from epilepsy. Clinicians should be sensitive in identifying psychopathology since this may lead to effective interventions for this group of children.

\section{KEYWORDS}

Epilepsy, Psychiatric Morbidity, Temperament.

HOW TO CITE THIS ARTICLE: Chougule NP, Chougule KN, Kale SS, et al. A study to determine psychopathology, psychiatric morbidity and temperament in epileptic children. J. Evolution Med. Dent. Sci. 2017;6(57):4267-4271, D0I: $10.14260 /$ Jemds/2017/924

\section{BACKGROUND}

Children with epilepsy are at increased risk for behavioural problems, as shown in both epidemiological and clinic-based studies. And children with new-onset and chronic seizures have an increased prevalence of behavioural problems compared to the general population or control groups. ${ }^{1}$

Epilepsy occurs in $0.5 \%-2 \%$ of the general population, the incidence of epilepsy in childhood is more than twice that in the adult population. ${ }^{2}$ Clinicians and researchers still have a limited understanding regarding the clinical presentation and aetiology of epilepsy, despite having such a huge burden on the population. Due to the atypical presentation in children, it is very common for a clinician to miss psychiatric morbidity of the clinical features of epilepsy. ${ }^{3}$

Financial or Other, Competing Interest: None.

Submission 13-05-2017, Peer Review 27-05-2017,

Acceptance 30-05-2017, Published 17-07-2017.

Corresponding Author:

Dr. Kaveri Chougule,

Senior Resident, Department of Psychiatry,

Dr. D. Y. Patil Medical College \&

Hospital, Kolhapur.

E-mail: dr.kaverinc@gmail.com

DOI: $10.14260 /$ jemds $/ 2017 / 924$

\section{(c) $($ ) $\odot$}

The prevalence of psychiatric morbidity and behaviour problems in children with epilepsy is largely unknown. Surveys that have been carried have thrown little light upon these issues because of the differences in criteria and methods of assessment. However, the overall picture suggests that although many children with epilepsy behave normally at school, proportionally many of them have learning and behavioural problems than their non-epileptic peers. Thus, children of epilepsy may be considered a high risk group for the development of such problems. The problems associated with behaviour are often overlooked because of preoccupation with the neurological aspect of such cases. ${ }^{4}$

Children suffering from epilepsy have to learn to cope with social apathy and neglect. Many of those who have written of the psychosocial problems associated with epilepsy have confidently asserted that these are almost always caused by public discrimination arising out of the perception of epilepsy as stigmatising. ${ }^{5}$

Behavioural problems are frequent in children with epilepsy. They are sometimes more severe than the convulsions itself and may be the reason deemed for institutional care. Opinions differ as to whether conduct disorders are due to the cerebral neuronal disorder which 
manifests itself as epilepsy or whether the symptoms are due entirely to the child's reaction to his illness. ${ }^{6}$

Temperament is a characteristic phenomenon in an individual's nature which include his susceptibilities to an emotional situation, his customary strength and speed of response, the quality of his prevailing mood, and also all the peculiarities of fluctuation and intensity of mood. This phenomenon is dependent on one's constitutional makeup, and is therefore hereditary in origin. ${ }^{7}$

Just like intelligence, temperament too has been conceptualised upon the basis of one's broad personality disposition, rather than specific traits in an individual that differentiates itself during the process of development. There is an availability of extensive data which is consistent as well, and these suggest that infants and young children differ strikingly in their behavioural characteristics. ${ }^{8,9}$ It is possible that certain characteristics are more stable than others; more global levels of analysis such as measuring general difficulties and stubbornness, might capture the essence of temperament better than a molecular behavioural measure. ${ }^{10}$

In a survey of all children with epilepsy from the Isle of Wight, the prevalence of psychiatric disorder in children with uncomplicated epilepsy was $28.6 \%$ which was four times the control rate. This percentage rose to $58.3 \%$ in those children who suffered brain damage as well. ${ }^{11}$

A psychiatrist often attends to the problem of epilepsy in children, as well as the behavioural problems or temperamental changes associated with it. Since epilepsy is perceived as a key problem, parents sometimes tend to handle the child differently than other siblings in the form of overprotection. ${ }^{12}$

Deriving insight from all the above facts an attempt has been made to study the probable factors which play a significant role in bringing about the psychiatric morbidity in children suffering from epilepsy.

\section{Aims and Objectives \\ 1. To know the association between the epilepsy and the psychiatric morbidity. \\ 2. To study the temperament in epileptic children.}

\section{MATERIALS AND METHODS}

The present study is a descriptive comparative study which was conducted in a tertiary care teaching hospital in NaviMumbai during the period of 6 months after obtaining ethical clearance for the study from the institutional ethical committee.

\section{Sampling Method}

Systematic sampling technique was used to select the study participants from the patients attending the paediatric epilepsy clinic. Every $5^{\text {th }}$ child with epilepsy was selected randomly for the study. Similarly, every $5^{\text {th }}$ child without epilepsy attending Psychiatry Clinic was selected as the control. In such a way fifty children in the age range of 4-14 years who had attended Paediatric Epilepsy Clinic during the period of the study were selected. These children matched for age, sex and socio-economic strata with no acute illness at the time of interview constituted the control group.

Informed consent was taken for the study from the parents and appropriate scales were administered. Parents of each child were explained about the nature of the study.
Confidentiality about the identity and data gathered was assured.

\section{Inclusion Criteria for Study Group}

1. Children suffering from epilepsy, in the age range of 4-14 years and whose parents were willing to give consent to participate in the study.

2. Those children with minimum duration of illness for more than 1 year were selected.

3. Past one year report of EEG suggestive of seizure disorder.

\section{Inclusion Criteria for Control Group}

Children attending Paediatric OPD of the same age group and socio-economic status with no medical or surgical illness and whose parents are willing to participate in study.

\section{Exclusion Criteria for Study and Control Group}

1. Parents who refused to give consent to participate in the study.

2. Children suffering from other chronic medical illnesses.

\section{Instruments Used}

1. Detailed Socio-demographic Proforma was prepared to gather information from the parent to clinically evaluate and collect the required data of each child.

2. CPMS - Childhood Psychopathology Measurement Schedule.

3. TMS - Temperament Measurement Schedule.

\section{Childhood Psychopathology Measurement Schedule} (CPMS)

The scale is detailed procedural adaptation and standardisation of the Child behaviour checklist (CBCL) to the Indian situation developed by Malhotra et al in 1988. Childhood Psychopathology Measurement Scale or the CPMS, in its final form, is a bilingual scale, both in Hindi and English. It comprises 75 items with response rated as 'yes' ( 0 ) or 'no' (Score 1); this can be administered as an interview schedule or as a self-administered questionnaire; CPMS also serves as a useful guide to clinical interviewing. It is applicable to 4-14 years old children of both the sexes. Taking the cut-off score of 10 and above, CPMS can be used as a screening instrument in epidemiological studies as well. Total, and also specific factor scores can be used to quantify or categorise psychopathology, as also as to monitor the change in clinical condition during medical intervention. ${ }^{13}$

\section{Temperament Measurement Schedule (TMS)}

A temperament measurement schedule (TMS) for children was developed and standardised for use in India. The Temperament Measurement Schedule (TMS) in its bilingual form had items in Hindi and English and also the scoring instructions. Devised for children of both the sexes, between 4 and 14 years of age, the data obtained was based essentially on the emotionally disturbed children who attended the child guidance clinic, for measurement of their temperament before the onset of symptoms; normal children were also assessed on similar lines. ${ }^{14}$

In its final form the Temperament Measurement Schedule comprises 45 items, 5 items in each of the 9 variables is rated on a 5-point scale. Definitions are provided for the two 
extreme scores 1 and 5, with a midpoint at 3 . The scores lesser than 3 are conceived to be in the negative direction and those greater than 3 in positive direction depending on the intensity and the frequency of the behaviour measured by each item. Mean score of each variable is computed by dividing the total score by 5 .

\section{Statistical Analysis}

Statistical analysis was done using percentages, Chi square test and Unpaired t-test.

\section{DISCUSSION}

\section{Socio-demographic Characteristics of the Sample}

The present study involved 100 children aged between 4-14 years with a sample size of 50 children suffering from epilepsy and 50 healthy children as the control group with duly matched for age, sex and socio-economic strata. 58\% of the subjects were male and $42 \%$ were female and among control group $64 \%$ were male and $36 \%$ were female. Both the groups were statistically matched. Amongst the study group, the majority of children $(60 \%)$ were between the age group 10-14 years. The control group was statistically matched for age with the study group and majority of the children (58\%) were between 10-14 years of age in the control group. 58\% of children of the study group were from lower socio-economic class, $32 \%$ from middle and $10 \%$ from the upper socioeconomic strata. The control group was matched for socioeconomic class with study group wherein, $60 \%$ were from lower, $30 \%$ from middle and $10 \%$ from the upper socioeconomic class.

Amongst the children in the study group, $72 \%$ were right handed, $22 \%$ left handed and $6 \%$ were ambidextrous. While in the control group $76 \%$ were right handed, $22 \%$ left and $2 \%$ were ambidextrous.

\section{RESULTS}

\begin{tabular}{|c|c|c|c|c|}
\hline \multirow{2}{*}{$\begin{array}{c}\text { CPMS } \\
\text { Score }\end{array}$} & \multicolumn{2}{|c|}{ Study Group } & \multicolumn{2}{c|}{ Control Group } \\
\cline { 2 - 5 } & $\mathbf{N}$ & $\mathbf{\%}$ & $\mathbf{n}$ & $\mathbf{\%}$ \\
\hline CPMS $<10$ & 28 & 56 & 38 & 76 \\
\hline CPMS $>10$ & 22 & 44 & 12 & 24 \\
\hline Total & 50 & 100 & 50 & 100 \\
\hline Table 1. Prevalence of Psychiatric Morbidity among Study \\
and Control Group \\
\hline
\end{tabular}

All children from the subject and the control group were screened for psychopathology using the childhood psychopathology measurement schedule. The Table 1 shows $44 \%$ of children from the study group had some psychiatric disturbance whereas $56 \%$ did not have any detectable psychopathology. In comparison only $24 \%$ of the children from the control group demonstrated psychiatric disturbance and $76 \%$ did not have any obvious psychiatric pathology. This finding simply implies that children suffering from epilepsy are at a higher risk of developing psychiatric disturbance than the non-epileptic children.

Psychiatric morbidity is strongly associated with epileptic children than non-epileptic children and this difference was statistically significant ( $p$ value of 0.035 as per Chi-square test). This finding corresponds to the finding of Ruther et al in their Isle of Wight study that $58.3 \%$ of patients with brain damage and epilepsy had psychiatric disturbances. ${ }^{9}$

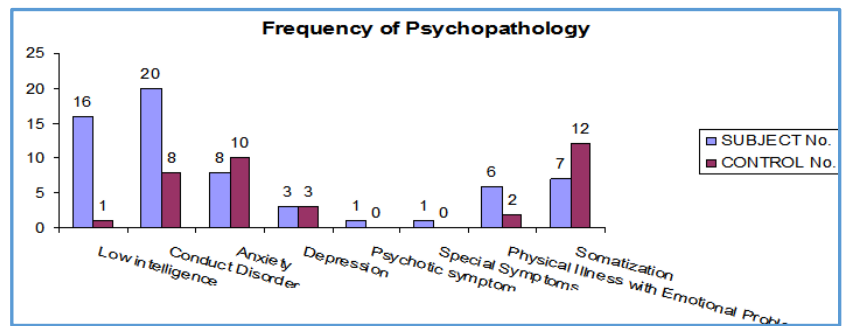

Figure 1. Showing Diagnostic Distribution According to CPMS

Majority of children in the study group had low intelligence with behavioural problems (32\%) and/or conduct disorder $(40 \%)$ whereas psychotic symptoms were not common $(2 \%)$ as show in figure-1.

Shukla and Katiyar noted that behaviour disorder was the commonest diagnosis in their study group. ${ }^{15,16}$ Lennox found mental inadequacy to be the commonest diagnosis in epileptics. Anxiety and conduct disorder (20\% and 16\%) respectively were common in children in the control group. ${ }^{17}$ Hence, it may be concluded that a low intelligence with behavioural problems and problems of conduct disorder is common association to epilepsy as an illness in childhood.

\begin{tabular}{|c|c|c|c|c|}
\hline \multirow{2}{*}{ Type of Epilepsy } & \multicolumn{2}{|c|}{ CPMS $<\mathbf{1 0}$} & \multicolumn{2}{c|}{ CPMS $>\mathbf{1 0}$} \\
\cline { 2 - 5 } & $\mathbf{n}$ & $\mathbf{\%}$ & $\mathbf{n}$ & $\mathbf{\%}$ \\
\hline GTC & 18 & 54.5 & 15 & 45.5 \\
\hline Petit & 2 & 25 & 6 & 75 \\
\hline TLE & 4 & 100 & 0 & 0 \\
\hline Focal & 3 & 100 & 0 & 0 \\
\hline Mixed & 1 & 50 & 1 & 50 \\
\hline Total & $\mathbf{2 8}$ & $\mathbf{5 6}$ & $\mathbf{2 2}$ & $\mathbf{4 4}$ \\
\hline \multicolumn{3}{|c|}{ Table 2. Type of Epilepsy and Psychopathology }
\end{tabular}

Children were screened using CPMS scale, where in 28 $(56 \%)$ out of the 50 patients studied a score below the cut-off of $<10$ was noted; whereas $22(44 \%)$ scored $>10$ on the CPMS scale. Amongst the 22 (44\%) whose score was above 10, $68.2 \%$ suffered from generalised tonic-clonic type of epilepsy, $27.3 \%$ had petit mal epilepsy and $4.5 \%$ the mixed type as per Table-2. Children with temporal lobe epilepsy and focal type of epilepsy did not have any significant psychiatric morbidity. Unpaired t-test was applied for this data and t-value was 0.28191 with $p$-value 0.392586 which indicates that there is no statistically significant difference between the CPMS score and types of epilepsy in study group.

Although earlier studies carried by Stores shows that temporal lobe epilepsy is associated with psychological disabilities, especially when the pathology is left sided, our study could not replicate those findings. ${ }^{18}$

Proximity to the limbic system and at times because of the limbic involvement itself in individuals with temporal lobe epilepsy is a plausible explanation for the emotional and behavioural problems and this reason has been derived as much from earlier studies, however, in our study it may be speculated that the focal nature of the epileptic involvement was not to an extent that a limbic reach took place at all, and hence the patients in this study were spared the emotional and behavioural implications of the temporal lobe epilepsy.

Also, focal seizure implies a focal cerebral involvement as compared to a more generalised disturbance of cerebral neuronal activity which occurs in a generalised seizure state. Also, it is worthwhile to remark that our sample size itself was rather small to draw a substantial comparison. 


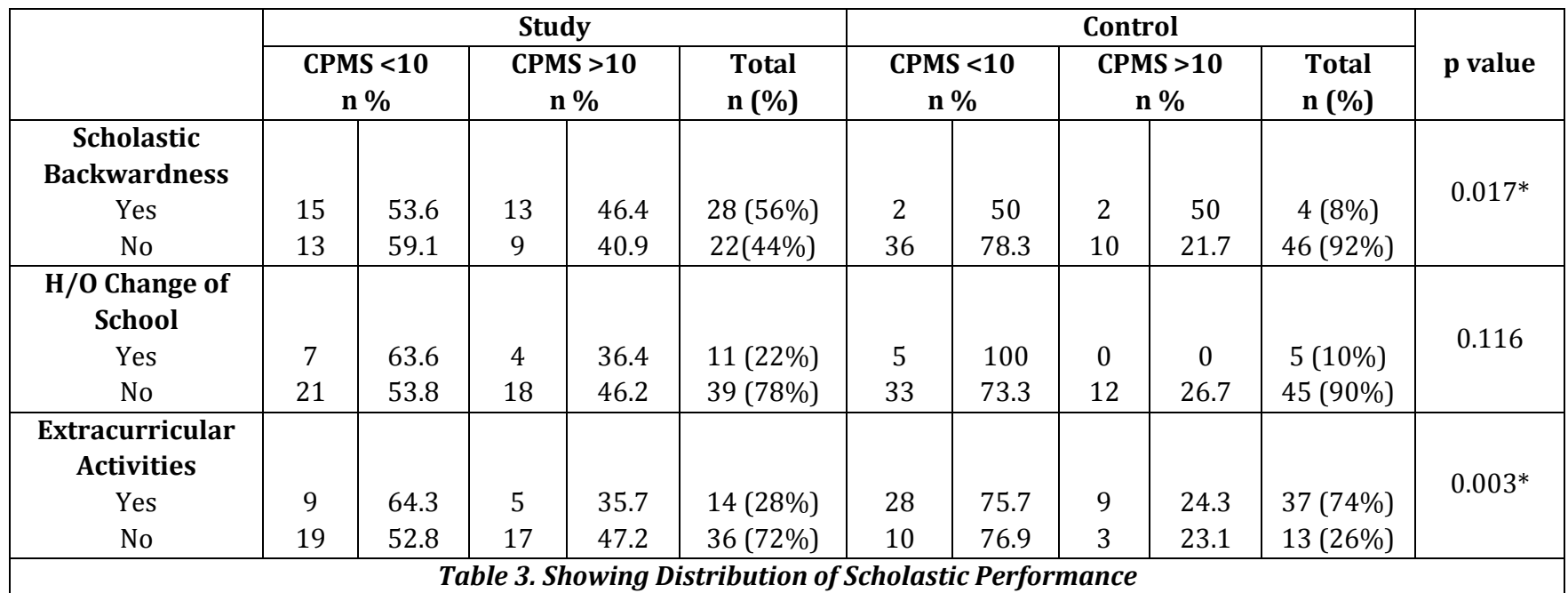

The above Table No.3 showing distribution of Scholastic Performance Amongst 56\% children from the study group who had scholastic backwardness, nearly $50 \%$ of them had significantly demonstrable psychopathology, whereas in control group only $8 \%$ had scholastic backwardness of which only half had developed psychological disturbance. Using Chisquare test the difference between the CPMS score and scholastic backwardness in study and control groups was found to be statistically significant ( $p$ - value $<0.05$ ).It may be argued that these children generally are low on self-esteem and perceived that their illness thwarted their aspirations and desires; also the parental care of these patients was such, that it smothered the child with overprotection, compromising at times upon the educational needs, thus overall stifling scholastic growth.

A history of change of school was not found statistically significant in the development of psychopathology in both the subject and the control group. Stores mentions that the social isolation of epileptic children, can lead to emotional problems. ${ }^{18}$ These children were often looked upon with sympathy from neighbours and friends thus amplifying the individual's sense of weakness and a lowered self-esteem; as also being ostracised in certain social settings kept the child away from extracurricular activities. And if at all there was intent to partake in extracurricular activities, their peers often disallowed them to be a part of their social and play activity. Hence, it may be surmised that psycho-social factors, apart from the biology of the seizure itself affected the child's participation in extracurricular activity and also led to other demonstrable psychopathologies and scholastic backwardness.

Almost two thirds (72\%) of children from the study group had no extracurricular activities, in comparison to only $26 \%$ children from control group. Upon application of 'Chi-square Test', the difference between the CPMS score and the extracurricular activities in subject and control group was found to be statistically significant ( $p$ value $<0.05$ ).

\begin{tabular}{|c|c|c|c|c|c|}
\hline \multirow{2}{*}{ TPMS } & \multicolumn{2}{|c|}{ Study } & \multicolumn{2}{c|}{ Control } & \multirow{2}{*}{ v value } \\
\cline { 2 - 6 } & Mean & S.D. & Mean & S.D. & \\
\hline $\begin{array}{c}\text { Approach } \\
\text { Withdrawal }\end{array}$ & 2.828 & .189 & 2.804 & .182 & .512 \\
\hline Adaptability & 2.784 & .155 & 2.800 & .161 & .615 \\
\hline Threshold & 2.788 & .178 & 2.796 & .164 & .816 \\
\hline
\end{tabular}

\begin{tabular}{|c|c|c|c|c|c|}
\hline Responsiveness & & & & & \\
\hline Mood & 2.820 & .190 & 2.772 & .145 & .161 \\
\hline Persistence & 2.808 & .180 & 2.800 & .180 & .825 \\
\hline Activity Level & 3.660 & .728 & 2.800 & .171 & $.000^{*}$ \\
\hline Intensity & 3.368 & .398 & 2,772 & .145 & $.000^{*}$ \\
\hline Distractibility & 3.256 & .491 & 2.796 & .164 & $.000^{*}$ \\
\hline Rhythmicity & 2.984 & .413 & 2.800 & .161 & $.050^{*}$ \\
\hline \multicolumn{7}{|c|}{ Table 4. Temperament Measurement Schedule }
\end{tabular}

On TMS from Table no. 4, the children from the study group had high scores on the following variables, viz. activity level, intensity, distractibility and rhythmicity. As per Chisquare test, the difference between the temperaments in the study and the control group was found to be significant for activity level, intensity, distractibility and rhythmicity ( $p$ value $<0.05$ ) while there was no statistically significant association among approach withdrawal, adaptability, threshold responsiveness, mood and persistence with both study and control groups.

\begin{tabular}{|c|c|c|c|}
\hline TMS & $\begin{array}{c}\text { CPMS<10 } \\
\text { n (\%) }\end{array}$ & $\begin{array}{c}\text { CPMS }>10 \\
\mathbf{n}(\mathbf{1 0})\end{array}$ & $\begin{array}{c}\text { Total } \\
\mathbf{n}(\%)\end{array}$ \\
\hline Activity level & $2(10.5 \%)$ & $17(89.5)$ & $19(38)$ \\
\hline Intensity & $1(5.6 \%)$ & $17(94.4)$ & $18(36)$ \\
\hline Distractibility & $1(9.1 \%)$ & $10(90.9)$ & $11(22)$ \\
\hline Rhythmicity & $1(20 \%)$ & $4(80)$ & $5(10)$ \\
\hline \multicolumn{3}{|c|}{$\begin{array}{c}\text { Table 5. Comparison between Variables } \\
\text { of TMS and CPMS among Study Group }\end{array}$} \\
\hline
\end{tabular}

From Table 5, it was concluded that there are no significant changes noted in the following temperament variables: approach withdrawal, adaptability, threshold of responsiveness, mood and persistence with respect to psychopathology in both subject and the control groups.

In study group, the temperament variables which had high scores with respect to the psychopathology were activity level, intensity, distractibility and rhythmicity.

After application of Unpaired t-test, statistically significant difference was observed between psychopathology and the individual variables of TMS such as activity level, intensity, distractibility and rhythmicity.

\section{CONCLUSION}

1. Psychiatric morbidity is strongly associated with epileptic children than non-epileptic children and this difference was statistically significant. 
2. There is no statistically significant difference between the CPMS score and types of epilepsy in study group.

3. Scholastic backwardness and extracurricular activities are definitely affected among epileptic children compared to non-epileptic.

4. Epileptic children scored high on variables of TMS like activity level, intensity, distractibility and rhythmicity.

\section{REFERENCES}

[1] Kanner AM, Soto A, Gross-Kanner H. Prevalence and clinical characteristics of postictal psychiatric symptoms in partial epilepsy. Neurology 2004;62(5):708-13.

[2] Kotsopoulos IA, van Merode T, Kessels FG, et al. Systematic review and meta-analysis of incidence studies of epilepsy and unprovoked seizures. Epilepsia 2002;43(11):1402-9.

[3] Saha R, Srivastava MK, Anand KS. Psychiatric presentation of childhood epilepsy: case series and review. Journal of Pediatric Neurosci 2016;11(4):36772.

[4] Bakwin H, Bakwin RM. Behavior disorders in children. $4^{\text {th }}$ edn. WB Sounders \& co 1972:154-63.

[5] Bagadia VN, Jeste DV, Chargoankar AS, et al. Psychological study of 180 cases of epilepsy. IJP 1973;15:391.

[6] Dutta SS, Premkumar TS, Kumar S, et al. Behaviour problems in children and adolescents with seizure disorder; association and risk factors. Seizure 2005;14(3):190-7.

[7] Allport GW. European and American theories of personality. In: David HP, Bracken VH (eds). Perspective in personality theory. Basic Book, New York 1961:P 324.
[8] Bates JE. The concept of difficult temperament. MerrilPalmer Quarterly 1980;26(4):299-319.

[9] Thomas A, Chess S. Temperament and development. New York: Brunner/Mazel 1977.

[10] Malhotra S. Temperament characteristics of children with conduct and conversion disorders. Indian Journal of Psychiatry 1989;31(2):168-72.

[11] Rutter M, Sandberg S. Epidemiology of child psychiatric disorder: methodological issues and some substantive findings. Child Psychiatry and Human Development 1985;15(4):209-33.

[12] Flor-Henry P. Epilepsy and psychopathology in recent advances in clinical psychiatry. In: Granville-Grossman K. Churchill Livingstone, Edinburgh, London, New York 1976.

[13] Malhotra S, Verma VK, Verma SK, et al. Childhood psychopathology measurement schedule: development and standardization. IJP 1988;30(4):325-31.

[14] Malhotra S. Children's temperament: factorial validity. Journal of Clinical Psychology 1983;10:399-406.

[15] Shukla GD, Srivastava ON, Katiyar BC, et al. Psychiatric manifestations in temporal lobe epilepsy: a controlled study. BJP 1979;135(5):411-7.

[16] Shukla GD, Katiyar SC. Psychiatric disorders in children with temporal lobe epilepsy: a controlled investigation. IJP 1981;23(1):62-5.

[17] Lennox WG, Lennox MA. Epilepsy and related Disorders. 1st edn. Vol: 1-2, Little Brown and Co 1960.

[18] Stores G. Behavioral aspects of childhood epilepsy, in research progress in epilepsy. Rose C (edr). Pitman, London 1983. 